\section{DIÁNOIA}

Diánoia

ISSN: 0185-2450

dianoia@filosoficas.unam.mx

Universidad Nacional Autónoma de

México

México

\title{
BEUCHOT, MAURICIO
}

Elementos esenciales de una hermenéutica analógica

Diánoia, vol. LX, núm. 74, mayo, 2015, pp. 127-145

Universidad Nacional Autónoma de México

Distrito Federal, México

Disponible en: http://www.redalyc.org/articulo.oa?id=58438810006

- Cómo citar el artículo

- Número completo

- Más información del artículo

- Página de la revista en redalyc.org

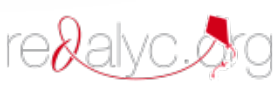

Sistema de Información Científica

Red de Revistas Científicas de América Latina, el Caribe, España y Portugal Proyecto académico sin fines de lucro, desarrollado bajo la iniciativa de acceso abierto 


\title{
Discusión
}

\section{Elementos esenciales de una hermenéutica analógica*}

\author{
MAURICIO BEUCHOT \\ Instituto de Investigaciones Filológicas \\ Universidad Nacional Autónoma de México \\ mbeuchot50@gmail.com
}

\begin{abstract}
Resumen: Mi propósito en este trabajo es ofrecer un panorama de la hermenéutica analógica. Comienzo con un breve recorrido histórico de la hermenéutica y de la noción de analogía. Reúno después ambos conceptos y explico cómo la hermenéutica analógica puede evitar las fallas tanto del univocismo como del equivocismo en la interpretación.
\end{abstract}

Palabras clave: analogía, univocismo, equivocismo, Gadamer, Ricœur

\begin{abstract}
The purpose of this work is to give a general sketch of an analogical hermeneutics. I start with a brief historical survey of hermeneutics and of the notion of analogy. I then put together both terms and explain how an analogical hermeneutics can avoid the faults of both univocism and equivocism in interpretation.
\end{abstract}

Key words: analogy, univocism, equivocism, Gadamer, Ricœur

\section{Introducción}

Se me ha pedido que exponga los rasgos fundamentales de la hermenéutica analógica. Para ello comenzaré con la descripción de las notas básicas de la hermenéutica, después introduciré la noción de la analogía y terminaré con la conjunción de estas dos en una hermenéutica analógica, es decir, en un instrumento de interpretación que aproveche la analogía para su trabajo.

Pero antes diré algo acerca del puesto de la hermenéutica en el cosmos filosófico actual. Se ha dicho que, después de la edad del análisis, ahora estamos en la edad de la interpretación, todavía dentro del giro lingüístico. Esto indica la actualidad de la hermenéutica, la cual es muy

*Este texto fue leído y discutido durante la Cátedra Diánoia el 3 de septiembre de 2014 en el Instituto de Investigaciones Filosóficas de la UNAM. La Cátedra Diánoia es un evento académico que organiza la revista Diánoia cada dos años para fomentar y celebrar la producción filosófica original en lengua española. 
semejante en sus objetivos a la pragmática, esa rama de la semiótica que va después de la sintaxis y la semántica, y que es la más difícil, porque atiende a lo que quiere decir el hablante. Y en la filosofía analítica se habla de un giro pragmático, después del positivista, ya que este último ha quedado muy atrás.

Gianni Vattimo incluso dice que la hermenéutica es el lenguaje común o koiné de la filosofía reciente, pero parece referirse a la que denominamos posmoderna. Lo que sí es seguro es que nuestra labor principal en las humanidades es interpretar textos. Lo hacemos en filosofía, literatura, historia o derecho. Recientemente en algunas ciencias como la antropología, la sociología y la psicología se ha llegado a cobrar conciencia de ello.

\section{La hermenéutica}

Comencemos con una definición de hermenéutica. Sé que hay varias concepciones de ella, pero no creo que descuide sus notas sustantivas si la caracterizo como la disciplina que versa sobre la interpretación de textos. ${ }^{1}$ Digo "disciplina" porque puede discutirse si la hermenéutica es ciencia o arte, y yo creo que tiene algo de los dos. No es, ciertamente una ciencia estricta, pero tampoco es una mera técnica o intuición artística. Me satisface más la relación que establece Gadamer entre la hermenéutica y la phrónesis aristotélica ${ }^{2}$ o prudencia, porque es el conocimiento en el contexto, la razón contextuada. Interpretar es comprender en profundidad, y el texto puede ser de varias clases, no sólo escrito. Gadamer añade a los tipos de texto el diálogo y Ricœur la acción significativa, y un texto también puede ser una pintura, una escultura, etcétera. Para Heidegger la realidad misma es texto, y por eso su ontología era una "hermenéutica de la facticidad", ${ }^{3}$ y por ello también Gadamer hablaba de la universalidad de la hermenéutica, pues en todo lo que hacemos interpretamos. ${ }^{4}$

Podría decirse que la phrónesis, una virtud ética, no tiene nada que ver con la hermenéutica, que parece ser algo teórico. Sin embargo, Gadamer muestra cómo en ambos casos se trata de una racionalidad

${ }^{1}$ Recojo los rasgos esenciales de la definición de hermenéutica de Paul Ricœur: "La hermenéutica es la teoría de las operaciones de la comprensión en su relación con la interpretación de los textos" (Ricœur 1982, p. 43).

${ }^{2}$ Gadamer 1994, p. 317.

${ }^{3}$ Grondin 2006, pp. 29 y ss.

${ }^{4}$ Gadamer 1977, pp. 567 y ss. 
situada, es decir, en contexto, ${ }^{5} \mathrm{y}$, precisamente, interpretar es poner un texto en su contexto. En el acontecimiento hermenéutico o acto interpretativo interviene, en primer lugar, un texto, que es lo que se va a interpretar. Pero ese texto supone un autor, así como un lector o intérprete, que es quien lo va a interpretar. Hay, por un lado, una intención del autor, que es lo que quiso expresar en su texto; y hay otra intencionalidad, la del lector, que no siempre interpreta lo que el autor quiso que se entendiera, sino que añade significados propios. Por eso algunos, como Umberto Eco, añaden una intencionalidad del texto para diferenciar la del autor y la del lector, y que es algo que resulta del encuentro de estos dos. ${ }^{6}$

Suele aclararse que únicamente el texto polisémico, es decir, el que tiene varios significados, permite la intervención de la hermenéutica, pues donde hay un solo significado no hace falta la interpretación. Este segundo caso sería el de la univocidad, la cual únicamente admite un solo sentido y, por lo mismo, una sola interpretación. Así, la hermenéutica conviene a textos multívocos, y la multivocidad es doble: 1) analógica o 2) equívoca. Sin embargo, la equivocidad plena tampoco admite la interpretación, pues la disuelve y la atomiza en infinitas interpretaciones sin que se sepa cuál es la o las verdaderas. En cambio, la analogía es una equivocidad controlada, como la definiera ya Aristóteles e incluso Bertrand Russell, quien hablaba de una ambigüedad sistemática ${ }^{7}$ (no de una ambigüedad sin más, pues ésta es inaprehensible).

La historia de la hermenéutica es larga. ${ }^{8}$ Sólo recordaré algunos hitos. En ella ha habido tendencias univocistas y equivocistas, así como analógicas. Se trata de una pugna entre el sentido literal y el sentido alegórico, en la que media un sentido analógico. Toda la historia de la hermenéutica podría vertebrarse mediante la lucha entre literalistas y alegoristas y la búsqueda de un terreno medio, analogista, que pocas veces se ha encontrado. En la Edad Media esto ocurrió en la hermenéutica de la Sagrada Escritura o exégesis bíblica. ${ }^{9}$ Ya desde el tiempo de la patrística, es decir, durante el comienzo del cristianismo y la época de los Santos Padres, la Escuela de Antioquía, capitaneada por Luciano, era literalista, privilegiaba el sentido literal de la Escritura, mientras que la Escuela de Alejandría, liderada por Orígenes, prefería el senti-

${ }^{5}$ Beuchot 2007a, pp. 82 y ss.

${ }^{6}$ Eco 1992, pp. 29 y ss.

${ }^{7}$ Russell 1960, pp. 14-24.

${ }^{8}$ Ferraris 2002, p. 12.

${ }^{9}$ Beuchot 2002, pp. 7-8.

Diánoia, vol. LX, no. 74 (mayo de 2015). 
do alegórico. Los literalistas argüían que la lectura alegórica llevaba a muchas herejías; pero lo curioso es que la única vez que Orígenes de Alejandría fue literalista incurrió en la heterodoxia. Por tomar al pie de la letra un texto evangélico, cayó en la herejía. Tuvo que venir el genio de San Agustín para lograr un equilibrio entre el literalismo y el alegorismo con el analogismo que ya empezaba a delinear él en su teología.

Ya en la época medieval, la exégesis de los monjes fue alegorista, mientras que la de los escolásticos fue literalista. ${ }^{10}$ Esto resulta comprensible debido a que a los monjes les interesaba la mística, el sentido espiritual, que incluía el sentido alegórico, y no el sentido literal o histórico, que era árido y plano. Empleaban como herramienta la retórica y la poética. En cambio, a los escolásticos les interesaba el sentido literal porque eran científicos; usaban la lógica o dialéctica. Ya no eran monjes, sino profesores universitarios (no se olvide que la universidad es un invento medieval). De entre los alegoristas sobresale Hugo de San Víctor. Uno de los literalistas más famosos fue Juan Duns Escoto. Sin embargo, hubo analogistas que lograron equilibrar el sentido literal y el alegórico con el sentido analógico, como San Buenaventura de Bagnoregio y Santo Tomás de Aquino, cada uno a su manera, pues el primero se inclinó más por la alegoría y el segundo por la literalidad. Ambos alcanzaron un balance muy equilibrado de ambas tendencias.

La hermenéutica siguió su avance en la historia y tuvo épocas literalistas, como el Renacimiento, en el que los humanistas buscaban la pureza filológica y los reformadores religiosos, como Lutero, prohibían la lectura alegórica de la Biblia. Si permitían el libre examen, era para procurar a toda costa el sentido literal. En el Barroco brotó un simbolismo tan extremo que se abusó muchas veces del alegorismo, y en la Ilustración la hermenéutica corrió el peligro de perecer por su rechazo de todo significado múltiple.

La Ilustración dio a luz dos hijos, uno por reacción y otro por eclosión, reñidos entre sí. El primero fue el Romanticismo, una rebelión contra el racionalismo del Iluminismo. El segundo fue el Positivismo, que llevó el cientificismo ilustrado hasta sus últimas consecuencias. El paradigma de la hermenéutica romántica se encuentra en la obra de Friedrich Schleiermacher, quien decía que interpretaba con la adivinación (divinatio) para entender al autor mejor de lo que se entendió él mismo, lo que condujo a un relativismo muy grande. ${ }^{11} \mathrm{El}$ paradigma

${ }^{10}$ Beuchot 2002, pp. 69 y ss.

${ }^{11}$ Schleiermacher 1987, p. 149. 
de la hermenéutica positivista lo representa John Stuart Mill, quien pedía que todo se sujetara a la razón y a la lógica. Gadamer y Ricœur hablan mucho de la hermenéutica romántica, a la cual juzgan excesivamente relativista, porque considera válidas a todas o a casi todas las interpretaciones. ${ }^{12}$ A ella la denomino equivocista. Podemos añadir una hermenéutica positivista, que en realidad no es hermenéutica porque sólo admite una única interpretación, pero que nos servirá en un sentido didáctico para contraponer el univocismo al equivocismo. También podemos decir que quien logra una postura intermedia, o una hermenéutica analógica, es Charles Sanders Peirce. En efecto, este filósofo se opone tanto a las pretensiones cientificistas del Positivismo como a los excesos de intuición del Romanticismo, y se coloca en un punto intermedio. Según él, se interpreta por abducción, la cual es una posición que se ubica entre la inducción y la deducción. Es la propuesta de hipótesis, que después se contrastan por inducción. ${ }^{13}$ De esta manera, se lanza una hipótesis interpretativa del texto y se trata de confirmarla con el grupo de investigadores o de intérpretes en la comunidad hermenéutica. Esto supo recogerlo Karl Otto Apel, quien durante un tiempo se posicionó en la hermenéutica y retomó de Peirce la idea de la intersubjetividad en la comunidad epistémica.

Dilthey estudió a Schleiermacher y llegó también a un relativismo interpretativo notable. De él la hermenéutica pasó a Heidegger, quien leyó a Dilthey por sugerencia de su amigo el teólogo y exégeta bíblico de Marburgo, Rudolf Bultmann. Heidegger supo combinar la hermenéutica con la fenomenología de su maestro Husserl. Llegó así a la hermeneutización de la fenomenología y a poner nuevamente en circulación la hermenéutica como postura filosófica. ${ }^{14}$ Esto fue durante la llamada "primera época" de Heidegger, la de Ser y tiempo, obra de 1927 en la que la hermenéutica tiene un papel muy importante (aunque ya figuraba antes, pues en un curso de 1923 el pensador alemán considera la ontología una hermenéutica de la facticidad). Sin embargo, Heidegger, en lo que se llama su "segunda época", abandona la hermenéutica, que recoge entonces su discípulo Hans-Georg Gadamer.

Gadamer es propiamente el gran hermeneuta del siglo Xx. ${ }^{15}$ En su libro Verdad y método de 1960 pone otra vez en circulación la hermenéutica. Si Heidegger la consideraba un existenciario del ser humano, es decir, algo que ya por el hecho de existir realiza el hombre, Gada-

\footnotetext{
12 Gadamer 1977, pp. 237 y ss.; Ricœur 1982, pp. 43 y ss.

13 Peirce 1970, pp. 65 y ss.

${ }^{14}$ Rodríguez 1997, pp. 101 y ss.

15 Grondin 2003, pp. 183 y ss.
} 
mer sigue en esa línea y opone la interpretación, como algo ontológico, al metodologismo de los positivistas lógicos. Considera que la interpretación se ubica en una tradición, y que es algo que se efectúa con un sensus communis, es decir, un contexto social, y que, además, tiene parecido con la phrónesis aristotélica. En este sentido, me parece que Gadamer apunta a la utilización de la analogía en la hermenéutica, ya que la phrónesis es analogía hecha vida, pues es sentido de la proporción y "analogía" fue el vocablo griego que los latinos tradujeron como proportio.

Tomando en cuenta a Gadamer, Ricœur desarrolló la hermenéutica sobre todo para la interpretación del símbolo y de la metáfora, ya que éstos no los abordaban ni el estructuralismo ni la filosofía analítica. Para Ricœur, el símbolo es el signo más rico, y le asigna la estructura de la metáfora. Es lo más difícil de interpretar, de modo que llega a decir que una hermenéutica muestra su valía cuando sirve para interpretar el símbolo, y una semiótica lo hace cuando da cuenta del significado de la metáfora. Ricœur estudia el símbolo en relación con el mito, que es una de las formas simbólicas, así como en relación con el psicoanálisis, que interpreta los sueños, los cuales tienen una estructura simbólica, y en relación con la metáfora, que presta su andamiaje al símbolo mismo. ${ }^{16}$

Éstos han sido los principales hermeneutas ya finados. Hoy en día hay varios representantes de esta disciplina, y me referiré a algunos de ellos a continuación. Pero antes pasemos a la noción de analogía.

\section{La analogía}

En la historia de la lógica y de la filosofía del lenguaje la analogía se define como un modo de significar y de predicar (es decir, de atribuir predicados a un sujeto) a medio camino entre la univocidad y la equivocidad. La univocidad es la significación idéntica de un término en relación con todos sus significados, como se ve en "hombre", que designa a todos sus individuos de la misma manera. En cambio, la equivocidad es la significación diferente de un término en relación con sus significados, como se ve en "gato", que puede significar cosas diversas: el animal doméstico, el instrumento mecánico, el juego de niños y hasta una persona demasiado servil. A diferencia de ambos, la analogía es la significación de un término en relación con sus significados en parte idéntica y en parte diferente. Por ejemplo, el bien significa y se predica

${ }^{16}$ Ricœur 1997, pp. 33 y ss.

Diánoia, vol. LX, no. 74 (mayo de 2015). 
de manera distinta pero proporcionalmente igual al bien útil, al bien deleitable y al bien honesto. ${ }^{17}$

El concepto de analogía tiene también su historia. Lo introdujeron en la filosofía los pitagóricos, presocráticos que tomaron esa idea de las matemáticas y la aplicaron a la filosofía. ${ }^{18}$ Significaba el sentido de la proporción, que ellos predicaban en la medicina y en la ética. Era la armonía que se alcanzaba mediante la proporción de los elementos constitutivos de una cosa. Además, la analogía les permitía considerar las propiedades físicas desde las matemáticas, concretamente desde la geometría, e incluso aplicar esto a la psicología para alcanzar el equilibrio del alma. Si se consulta el tercer tomo de la obra clásica de Hermann Diels y Walter Kranz, Die Fragmente der Vorsokratiker, y se busca el vocablo "analogía", se verá que lo emplearon principalmente los pitagóricos, ${ }^{19}$ claro que tras la mediación de los doxógrafos, pero es significativo que se encuentra en ellos, sus progenitores filosóficos.

Esta idea pasa de los pitagóricos a Platón, quien tuvo varios amigos que dan nombre a algunos de los Diálogos (Timeo de Locres, Teeteto y Lisis, entre otros). Platón practica la analogía mendiante el empleo de mitos en su filosofía. ${ }^{20}$ Cuando se topa con algo muy importante suele introducir un mito, como si de ahí se pudiera extraer la explicación de ese tema. ${ }^{21}$ Sin embargo, también utiliza la analogía o proporción para presentar las virtudes de los ciudadanos en la República (la prudencia, la templanza, la fortaleza y la justicia). Todas ellas son virtudes analógicas, basadas en la idea de proporción.

Aristóteles recibe la analogía de su maestro Platón, tanto la analogía de proporcionalidad, de origen pitagórico, como una analogía más platónica, más jerarquizante, la analogía de atribución o pros hen. Ésta es muy importante en su sistema porque los principales conceptos de la filosofía son analógicos o, como expresa él, cada uno de ellos "se dice

${ }^{17}$ Una definición clásica es la siguiente: "El nombre análogo significa al mismo tiempo varios conceptos, pero no como en desorden, sino como coordinados o subordinados, a saber: uno de manera primera y principal, otro u otros de manera secundaria y por cierta extensión, atribución o transunción, esto es, subordinados al primero y principal, o muchos coordinados según relaciones o proporciones semejantes, y por ello no significa del todo lo mismo en todos ellos" (Ramírez 1970, pp. 276-277).

${ }^{18}$ Secretan 1984, p. 19.

${ }^{19}$ Diels y Kranz 1967, p. 43b34. Se trata de Pitágoras y Arquitas de Tarento. Sólo se añade a Espeusipo, el sobrino de Platón, que fue más bien pitagórico, y a Hipócrates, que también lo fue en buena medida.

${ }^{20}$ Grenet 1948, pp. 52 y ss.

${ }^{21}$ Pieper 1998, p. 38. 
de muchas maneras" (pollajós légetai), como lo vemos en el libro V de la Metafísica, que es una especie de diccionario filosófico. No obstante, aun cuando cada término filosófico (p. ej. el ente, el uno o el bien) se dice de muchas maneras, se dice en relación con un principal (alla pros hen), es decir, con cierto orden, pros hen o ad unum. Por ejemplo, el ente se dice de muchas maneras, pero de modo principal de la substancia, y luego, en relación con ella, de las demás categorías: la cantidad, la cualidad, la relación, la acción, la pasión, el tiempo, el lugar, la situación y el hábito. Con todo, la doctrina de la analogía del ente (analogia entis), como lo ha dicho Pierre Aubenque, no es propiamente aristotélica, sino medieval, ${ }^{22}$ aunque está claro que se basa en elementos de Aristóteles. ${ }^{23}$ Por eso pasaremos a los desarrollos escolásticos.

La teoría de la analogía atraviesa la Edad Media, y encuentra en Santo Tomás a alguien que la aplicó tanto a la filosofía como a la teología. Sin embargo, encontró un gran sistematizador en un tomista del Renacimiento, Tomás de Vio (1469-1534), el cardenal Cayetano, llamado así porque fue obispo de Gaeta —en latín Caieta—, en Italia. Este autor, en su libro De nominum analogia, ofrece una clasificación muy útil. Distingue tres tipos de analogía: de desigualdad, de atribución y de proporcionalidad, tanto propia como impropia o metafórica. La analogía de desigualdad tiene poca utilidad, ya que se acerca demasiado a la univocidad (por ejemplo, la semejanza en un mismo género, como la que hay entre la fuerza física y la fuerza espiritual o moral). La analogía de atribución es el famoso pros hen de Aristóteles, y que Cayetano llamó analogia attributionis, pues es la asignación diversa de un predicado a diversos sujetos, según un orden que va de más propio a menos propio; por eso admite un analogado principal y analogados secundarios. Un ejemplo es "sano", que se atribuye propiamente al organismo, pero también al alimento porque mantiene la salud y al medicamento porque la restablece, así como al clima, al ambiente e incluso, metafóricamente, a la amistad (ahora diríamos que a la economía, pues se habla de una economía "sana"). La analogía de proporcionalidad propia ocurre, por ejemplo, al decir "el instinto es al animal lo que la razón al hombre", y la analogía de proporcionalidad impropia o metafórica tiene lugar, por ejemplo, en "las flores son al prado lo que la risa al hombre", proporción que nos hace entender la metáfora "el prado ríe". ${ }^{24}$

La teoría de la analogía llegó después a Franz Brentano, quien escribió una tesis de doctorado titulada Sobre el múltiple significado del

${ }^{22}$ Aubenque 1989, pp. 291-304.

${ }^{23}$ de Libera 1991, pp. 82-85.

${ }^{24}$ Thomas de Vio 1952, pp. 4 y ss. 
ser en Aristóteles, en 1862. En ese trabajo abordó el tema de la analogía del ente, tan importante para el Estagirita, pero se inclinó por la univocidad, tal vez como concesión a sus enemigos los positivistas. Por eso, aunque Heidegger dice en una página autobiográfica que el primer libro filosófico que leyó fue esa célebre tesis de Brentano, ${ }^{25}$ hizo poco caso de la analogía y se inclinó por la univocidad. No en balde escribió su tesis de habilitación (Habilitationschrift) sobre Juan Duns Escoto, el campeón de la univocidad en la Edad Media, y eso también se reflejó en Ser y tiempo, donde usa mucho la teoría escotista de la individuación a través de la haecceitas, puesta allí como el Dasein. ${ }^{26}$

Sin embargo, la doctrina de la analogía se preservó por otro camino, un tanto extraño, gracias a Charles Sanders Peirce quien, en la pasmosa erudición que lo caracterizó, fue un gran conocedor de los medievales. A pesar de que admiraba a Duns Escoto, y que lo siguió en el problema de los universales, mantuvo la idea de la analogía y, más aún, la actitud analógica en el conocimiento. ${ }^{27}$ Peirce recoge la analogía en su idea de la iconicidad, del signo icónico. En efecto, divide el signo en tres tipos: ícono, índice y símbolo. ${ }^{28} \mathrm{El}$ índice es el signo unívoco, porque es natural, surge de una relación de causa y efecto, como la huella en el lodo y el animal que la imprimió. El símbolo es el signo equívoco porque es cultural, como el lenguaje, en el que una cosa (como la mesa) se dice de maneras diferentes en los distintos idiomas. En cambio, el ícono es en parte natural y en parte cultural, en parte idéntico y en parte diferente, como un simulador de un avión, donde se aprende a pilotear. Además, Peirce divide el ícono en tres: imagen, diagrama y metáfora. La imagen nunca es unívoca, es decir, idéntica a lo representado; es sólo semejante. La metáfora también ofrece conocimiento. Y el diagrama está entre la una y la otra, pudiendo ser desde una fórmula algebraica hasta una buena metáfora. Un estudioso suyo, Max Black, que fue,

${ }^{25}$ Nolte 1998, p. 36, cita el Discurso inaugural de Heidegger en la Academia de Ciencias de Heidelberg, de 1957, donde se lee: "En 1907, un amigo paterno oriundo de mi patria natal, el más tarde arzobispo de Friburgo de Brisgovia, Conrad Gröber, me dio en mano la disertación de Franz Brentano Del significado múltiple del ente según Aristóteles (1862) [...] La pregunta por la simplicidad de lo múltiple en el ser, que por entonces se despertaba sólo de forma oscura, vacilante y desvalida, siguió siendo a lo largo de muchos desmayos, extravíos y perplejidades el motivo constante del tratado Ser y tiempo, aparecido dos décadas después".

${ }^{26}$ Volpi 1976, pp. 134-135.

${ }^{27}$ Beuchot 2006, pp. 55-69; Beuchot 2009, pp. 29-39.

${ }^{28}$ Peirce 1974, pp. 45 y ss. 
asimismo, discípulo de Wittgenstein, dice, en la línea de Peirce, que los buenos modelos científicos fueron metáforas afortunadas. ${ }^{29}$

En la actualidad la noción de analogía ha sido trabajada en la filosofía analítica sobre todo por lógicos polacos, entre los que descuella Innocentius M. Bochenski, así como el estadounidense James F. Ross y el francés Stanislas Breton. Estudié con Bochenski, en la Universidad de Friburgo, Suiza, entre 1973 y 1974. Este autor había elaborado una lógica de la analogía, ${ }^{30}$ pero me pareció que su reconstrucción era demasiado complicada. Por eso decidí aplicarla a la hermenéutica y no a la lógica, que ya había sido trabajada por él. En el ámbito de la hermenéutica, la apreció mucho Ricœur, a quien pude tratar en 1987 y que me orientó hacia el camino de la analogía. Trataba yo entonces el problema de la interpretación del símbolo, y Ricœur me hizo releer la parte final de La simbólica del mal, y su gran libro La metáfora viva, obras en que discute la analogía. Ambos filósofos me llevaron a aplicar la analogía a la hermenéutica.

\section{Hermenéutica analógica}

Como he dicho, la hermenéutica es el instrumento para la interpretación de textos. ¿Qué le añade la noción de analogía? ¿Para qué sirve ésta en la interpretación?

En primer lugar, sirve como una actitud. Dada su raigambre aristotélica, la analogía tiene que colocarse en una epistemología de las virtudes, al modo como en la ética es la clave de las virtudes morales, a saber, la templanza, la fortaleza y la justicia, pues es el sentido de la proporción. En cuanto a las virtudes epistémicas, corresponde sobre todo a la phrónesis o prudencia, que es la sabiduría de lo concreto y práctico, el equilibrio proporcional; por eso también se refleja en la sofía o sabiduría, que es teórica, pero que ilumina a la praxis desde las alturas.

La noción de analogía tiene una importancia especial para la hermenéutica porque, como lo vio Gadamer, ésta tiene la estructura de la phrónesis, en tanto que saber situado y atento al contexto, y la phrónesis tiene el esquema de la proporción, la cual es el núcleo de la analogía. ${ }^{31}$

De este modo, una hermenéutica analógica tendrá como actitud característica, o como virtud propia, evitar los extremos de una hermenéutica univocista y de una hermenéutica equivocista. La primera, que

${ }^{29}$ Black 1964, p. 218.

${ }^{30}$ Bochenski 1962, pp. 96-117.

${ }^{31}$ Beuchot 2004, pp. 439-449; Beuchot 2007b, pp. 425-449. 
se coloca en el punto fijo de la univocidad, sólo acepta una única interpretación como válida y todas las demás las considera inválidas o inadecuadas. Ya que la hermenéutica supone que sólo puede aplicarse a un texto polisémico, una hermenéutica unívoca de hecho no podría existir, pero se da en los casos en los que se quiere reducir la polisemia a un único sentido, como cuando algunos hablan de haber obtenido la interpretación, por ejemplo, de Platón. En cambio, está claro que una hermenéutica equívoca, distendida en el ámbito inabarcable de la equivocidad, es algo que existe; es la hermenéutica relativista extrema que vemos hoy en día en muy numerosos hermeneutas, típicamente posmodernos. Esa hermenéutica equívoca considera válidas casi todas las interpretaciones, si no es que todas, alegando que no hay criterios claros para decidir cuándo una interpretación es adecuada y cuándo no. A diferencia de ambas, una hermenéutica analógica se abre lo suficiente, sin atomizarse, como la equívoca, a un sinfín de interpretaciones, pero no tiene la exigencia de unicidad de la unívoca. Si la hermenéutica unívoca aspira a la interpretación clara y distinta de un texto, la equívoca se derrumba en interpretaciones oscuras y confusas, por su excesiva aceptación de la ambigüedad y del relativismo. Como se ha visto, una hermenéutica analógica trata de colocarse entre las dos anteriores e intenta evitar los defectos y aprovechar los beneficios de ambas posiciones.

Asimismo, una hermenéutica analógica no sólo se distingue de la unívoca y la equívoca, sino que emplea las dos formas de la analogía, a saber, la analogía de proporcionalidad y la de atribución. En su aspecto de proporcionalidad, es capaz de aglutinar, conmensurar o coordinar varias interpretaciones de un texto por lo que tienen de común, es decir, busca el común denominador de éstas, a pesar de las diferencias que contienen. Iguala en lo posible; es la parte de identidad que tiene la analogía o semejanza. En su aspecto de atribución, es capaz de distinguir, atiende las diferencias $\mathrm{y}$, aprovechando su estructura jerárquica, nos ayuda a disponer de las varias interpretaciones de un texto de manera ordenada, según su mayor o menor adecuación al significado del texto. De modo que se puede establecer cuáles interpretaciones son los analogados principales y cuáles los secundarios, hasta que llega un momento en el que se hunden en la inadecuación, en la equivocidad y, además, no se alcanza la univocidad en la adecuación misma.

Por otro lado, la analogía de atribución se divide en intrínseca y extrínseca, de modo que habrá niveles de interpretación que serán muy apegados al significado del texto, de manera intrínseca y esencial, dando paso a una idea de verdad como correspondencia o adecuación, y 
otras de manera extrínseca y accidental, lo que permite una noción de verdad pragmática más amplia.

Asimismo, la analogía de proporcionalidad se divide en analogía de proporcionalidad propia y analogía de proporcionalidad impropia o metafórica. Es decir, una de sus formas es la metáfora. Solía asociarse a la propia el sentido literal y a la impropia o metafórica el sentido alegórico. Sin embargo, más recientemente se ha visto que la propia tiene la estructura de la metonimia y la impropia obviamente la de la metáfora. ${ }^{32}$ Así, la analogía tiende sus brazos y abarca de manera suave los dos sentidos de los textos, el literal y el alegórico, situándose en medio, de modo que puede oscilar hacia uno o hacia otro, según se necesite. También hemos visto que la analogía abarca la metáfora y la metonimia, que son los dos polos del discurso humano (la primera, de la poesía; la segunda, de la prosa). ${ }^{33}$

Con esto la analogía conjunta dos aspectos que el estructuralismo separaba de manera demasiado tajante. Es decir, habrá interpretaciones que sean más sintagmáticas y otras más paradigmáticas. ${ }^{34}$ Es decir, unas más superficiales y otras más en profundidad, como se da, respectivamente, en el sentido literal y en el metafórico.

Igualmente, se nos dice que el símbolo es el signo más rico, porque siempre tiene múltiples significados. ${ }^{35}$ Se juzga que es el signo más rico porque es el que más representa a una cultura. Una cultura se caracteriza por sus símbolos. Así lo han hecho ver filósofos y antropólogos como Ernst Cassirer. Luis Villoro hablaba de una identidad cultural, que radica en lo simbólico, y que era tan importante como la identidad ontológica de los individuos en una colectividad. ${ }^{36}$ Por ser tan rico y múltiple, el símbolo es el signo más difícil de interpretar y, por lo mismo, el que más le interesa a la hermenéutica.

¿Cómo interpretar el símbolo? Ya Kant, en la Crítica del juicio §59, nos dice que el símbolo sólo se puede conocer analógicamente, es decir, en el doble sentido de que únicamente se puede conocer por un procedimiento analógico y de que sólo alcanzamos de él un conocimiento analógico, nunca unívoco. Lo dice así:

${ }^{32}$ Sobre la analogía de proporcionalidad impropia como metáfora y la de atribución como metonimia, véase cómo las aplica a la física Selvaggi 1955, pp. 282-283.

${ }^{33}$ Jakobson 1986, p. 389.

${ }^{34}$ Sobre los ejes sintagmático y paradigmático véase la exposición en Saussure 1988, pp. 172 y ss.

${ }^{35}$ Ricœur 1995, p. 67.

${ }^{36}$ Villoro 1998, p. 66. 
Todas las intuiciones que se ponen bajo conceptos a priori son esquemas o símbolos, encerrando los primeros exposiciones directas de conceptos; los segundos, indirectas. Los primeros lo hacen demostrativamente; los segundos, por medio de una analogía (para la cual también se utilizan intuiciones empíricas), en la cual el juicio realiza una doble ocupación: primero, aplicar el concepto al objeto de una intuición sensible, y después, en segundo lugar, aplicar la mera regla de la reflexión sobre aquella intuición a un objeto totalmente distinto, y del cual el primero es sólo el símbolo. ${ }^{37}$

Kant pone como ejemplos representar un Estado como un organismo, cuando se rige por leyes, o como un molino, cuando se rige por la voluntad férrea del gobernante. Y añade algo fundamental de la analogía: "entre un Estado despótico y un molinillo no hay ningún parecido, pero sí lo hay en la reglas de reflexionar sobre ambos y sobre su causalidad". ${ }^{38}$ Es decir, recoge la idea de que la analogía no es una semejanza de propiedades, sino de relaciones. Una interpretación analógica es, para Kant, la que corresponde al símbolo.

Por su parte, Ricœur nos dice que la interpretación del símbolo tiene un esquema analógico; no en balde sostiene que el símbolo posee la misma estructura que la metáfora, y sabemos que la metáfora es una de las formas de la analogía. Ricœur afirma primero que el símbolo es signo, pero un signo muy especial, y explica: "Todo signo apunta a algo fuera de sí, y además lo representa y sustituye. Pero no todo signo es símbolo. Aquí hay que añadir que el símbolo oculta en su visual una doble intencionalidad". ${ }^{39}$ Es decir, tiene una intencionalidad o sentido literal y una intencionalidad o sentido analógico; por eso los signos simbólicos, sigue diciendo nuestro autor, "son opacos, porque el mismo sentido literal, original, patente, está apuntando a otro sentido analógico, que no se nos comunica más que a través de él [...] Esta opacidad constituye la profundidad misma del símbolo, que, como veremos, es inagotable". ${ }^{40} \mathrm{El}$ propio Ricœur añade:

Pero intentemos comprender debidamente ese lazo analógico que une el sentido literal con el sentido simbólico. Mientras la analogía es un razo-

${ }^{37}$ Kant 1958, pp. 443-444. En la nota a la página 443 Kant dice: "Lo intuitivo del conocimiento debe ser opuesto a lo discursivo (no a lo simbólico). Ahora bien, lo primero es: o esquemático, mediante demostración, o simbólico, como representación, según una mera analogía".

${ }^{38}$ Kant 1958, p. 444.

${ }^{39}$ Ricour 1969, p. 251.

${ }^{40}$ Ricœur 1969, p. 252.

Diánoia, vol. LX, no. 74 (mayo de 2015). 
namiento inconcluyente que procede por cuarta proporcional - $\mathrm{A}$ es a $\mathrm{B}$ como C es a D-, en el símbolo no podemos objetivar la relación analógica que empalma el sentido segundo con el primero; el sentido primero nos arrastra más allá de sí mismo, mientras nos estamos moviendo en el sentido primero: el sentido simbólico se constituye en y por el sentido literal, el cual opera la analogía proporcionando el análogo. ${ }^{41}$

Aquí se ve el sentido traslaticio que tiene el símbolo, es decir, su estructura metafórica, que también señala Ricœur, y que arrastra y conduce a algo diferente, al sentido propiamente simbólico. El símbolo tiene, pues, un componente de analogicidad, que, según hemos dicho, lleva inevitablemente a otra cosa. En el símbolo, el sentido literal está preñado ya del sentido analógico, está cargado de figuración; es una literalidad anómala. Nos conduce al otro sentido aunque no queramos, es un camino inevitable. El sentido manifiesto nos lleva de la mano al sentido latente.

Más aún, algunos mencionan que el símbolo no tiene sólo dos sentidos, sino que puede desatar incluso un sinfín de sentidos. Esto es discutible, o por lo menos tiene que acotarse. Pide un límite. Por eso algunos posmodernos, como Derrida, siguiendo a Nietzsche, hablan del carácter metafórico del lenguaje, pero añaden que no hay metafórica posible que nos lo revele. ${ }^{42}$ Solamente hay huellas que seguimos, sin que nunca alcancemos nuestra presa: el sentido.

Asimismo, una hermenéutica analógica nos ayudará a buscar no sólo el sentido de los textos, sino su referencia. Ahora son pocos los que defienden la referencia; más bien muchos la atacan y se quedan con el solo sentido. Pero una teoría de la interpretación analógica nos hace recuperar la verdad como correspondencia o adecuación, que es la que procede de Aristóteles, que Tarski recuperó para los lenguajes formales y Ricœur para la metáfora y el símbolo, ${ }^{43}$ sólo que en este último caso se trata de una referencia anómala. No es una referencia física o fisicalista, sino una referencia humana, ya que los símbolos, por ejemplo los mitos, no se refieren a hechos históricos, sino a hechos humanos, a cosas que el ser humano necesita para dar sentido a su vida.

La hermenéutica analógica nos ayudará a obtener una interpretación a la vez sintagmática y paradigmática —en el sentido del estructuralismo que he mencionado-, aunque preponderantemente del segundo tipo. Se ha pensado que las dos son irreconciliables, pero podemos ver

${ }^{41}$ Ricœur 1969, p. 252.

${ }^{42}$ Derrida 1989, p. 259.

${ }^{43}$ Ricœur 1995, pp. 58 y ss. 
el punto en el que se entrecruzan, en el que se unen en el trabajo interpretativo. El polo sintagmático es horizontal y superficial, avanza por oposición, como en el lenguaje ordinario, en el que los signos se dan in praesentia, se contraponen y así adquieren su función. El polo paradigmático es vertical y avanza en profundidad; se da in absentia (por la memoria) y procede por asociación, como los estilos de las columnas griegas. ${ }^{44}$ Este último cala hondo, asocia y ve lo que se repite, y que, a pesar de ello, tiene una novedad: la de lo mismo pero diferente (esto es: lo análogo). Por ejemplo, los monjes medievales leían los salmos en sentido paradigmático, asociativo, pues los relacionaban con toda la Escritura y de manera reiterativa, ya que los cantaban un buen número de veces al año y los sabían de memoria. Pero cada vez que los repetían, éstos eran diferentes, es decir, enseñaban algo nuevo: lo mismo se veía distinto.

La analogía tiene como instrumento principal la distinción, y por ello requiere del diálogo. Tiene que distinguir, porque eso es lo que evita la univocidad y la equivocidad. Según Peirce, la distinción era lo propio de la discusión escolástica, y agregaba que la distinción tiene la estructura de un silogismo dilemático o razonamiento alternativo. ${ }^{45}$ Además, la analogía es eminentemente dialógica. En efecto, el diálogo es el que obliga a distinguir, y la distinción hace encontrar con sutileza el medio entre dos extremos que se presentan como opciones de un dilema, ampliando la gama de interpretaciones. Si tomamos una de las alternativas del dilema, caemos en contradicción o en problemas; si adoptamos la otra, también. Entonces hay que buscar un tercer término, un término medio que nos ayude a introducir otra $u$ otras alternativas, que sean nuevas posibilidades, las cuales nos permitan salir de la contradicción que generalmente tiene lugar en los extremos.

Por otra parte, la hermenéutica presupone una antropología filosófica o filosofía del hombre en la que el ser humano se caracteriza por su humildad ante el saber. Sabe que puede no saber, que se puede equivocar, que puede engañarse o ser engañado. Sobre todo, que puede no tener razón. ${ }^{46}$ Eso mueve a sospechar y a distinguir. El ejercicio de la sospecha, en efecto, va muy asociado con la distinción, pues es el procedimiento por el que se busca salir del error posible. Distinguir es lo más hermenéutico, y la distinción es un acto sumamente analógico, ya que trasciende la identidad pura y la diferencia pura para colocarse

\footnotetext{
${ }^{44}$ Éstas son las definiciones y ejemplos de Saussure 1988 (pp. 173-174).

${ }^{45}$ Peirce 1988, pp. 201-203.

${ }^{46}$ Domingo Moratalla 1991, pp. 310-311.
} 
en la analogía, la cual se reconoce como no pura, aunque sabe también que no es completamente impura. Es la mediación en la que predomina la diferencia. Además, una hermenéutica analógica ayudaría a superar la dicotomía que señala Wittgenstein entre el decir y el mostrar. Es sabido que este autor separaba demasiado, sin punto de conciliación ni solución de continuidad, el decir y el mostrar. ${ }^{47}$ El decir era lo científico y el mostrar lo místico. Lo que no se podía decir, sólo se podía mostrar. Según el filósofo austríaco, las cosas más importantes de la vida, como lo ético, lo estético y lo religioso, no se pueden decir; sólo se pueden mostrar. Sin embargo, muchos místicos usaron la analogía para poder decir de alguna manera lo que estaba destinado a sólo mostrarse. Frente a la teología positiva, en la que se pretendía decir mucho acerca del misterio, se estableció la teología negativa (en la línea judía, como en Filón y Maimónides, y en la línea cristiana oriental, como en Juan Damasceno y Gregorio Palamás). Pero también se buscó una línea intermedia, como se aprecia en el caso del Pseudo Dionisio, cuando no se lo lee sólo como teólogo negativo, sino como si buscara la vía de la eminencia. Algo parecido sucede en Santo Tomás, en el Maestro Eckhart, en San Juan de la Cruz y otros. ${ }^{48}$ La analogía es decir el mostrar y mostrar el decir. Sobre todo tratar de decir lo que sólo se puede mostrar. Pero se sabía que eso únicamente era posible hasta cierto punto, en muy pequeña medida, como balbuciendo, con un gran predominio de las imágenes y las metáforas sobre el discurso directo y literal. Sin embargo, se consiguió al menos lo suficiente para decir algo del misterio y no quedarse irremediablemente callado.

Finalmente, me gustaría decir que la hermenéutica analógica tiene un carácter mexicano y universal. Mexicano, porque adopta de la historia de la filosofía en México muchos pensadores que, en diversos momentos, usaron la noción de analogía como núcleo de su filosofar. ${ }^{49}$ Esto ha tenido lugar desde los prehispánicos, como Netzahualcóyotl, quien emplea mucho la metáfora para reflexionar. Asimismo, Bartolomé de las Casas, quien trata de comprender la cultura indígena mediante una analogía con la griega y la romana, e incluso con elementos de la cristiana. A muchos de los dioses indios los compara con deidades griegas y romanas, y aun con santos del cristianismo, y, sobre todo, en contra de humanistas como Ginés de Sepúlveda, defiende un humanismo indígena, análogo al europeo, es decir, en parte igual pero predominantemente diferente. Alonso de la Vera Cruz compara los sacrificios

\footnotetext{
${ }^{47}$ Wittgenstein 1973, p. 87.

${ }^{48}$ Beuchot 1996, pp. 258-271; Beuchot 1993, pp. 29-34.

${ }^{49}$ Beuchot 2012, pp. 9 y ss.
} 
humanos con una especie de eucaristía en la misa católica. Tomás de Mercado usa la noción de analogía para su idea de la justicia conmutativa en el comercio. Zapata y Sandoval la emplea para su idea de la justicia distributiva y la adecuada asignación de oficios y beneficios civiles y eclesiásticos a los peninsulares y a los criollos. Francisco Javier Clavijero usa la analogía para defender la cultura indígena contra los ilustrados, quienes la menospreciaban. Clemente de Jesús Munguía deja un libro sobre la filosofía del lenguaje en el que expone la doctrina de la analogía. Ya en el siglo xx, José Vasconcelos escribe una obra sobre Pitágoras en la que expone algunos rasgos de esta teoría a través del ritmo y la armonía. Octavio Paz toma la analogía como núcleo de la poesía y de su pensamiento. Adolfo García Díaz, que formó parte del Instituto de Investigaciones Filosóficas y fue de los fundadores de la revista Diánoia, dejó una tesis de maestría sobre la analogía. Alejandro Rossi dice que el primer curso que dictó en México fue sobre la analogía, ${ }^{50}$ y Enrique Dussel aplica la analogía a la dialéctica, en forma de analéctica o anadialéctica.

\section{Conclusión}

He tratado de esbozar las líneas principales de una hermenéutica analógica a partir de la noción misma de hermenéutica y luego de la correspondiente de analogía. Al unirlas, se obtiene la hermenéutica analógica, una teoría de la interpretación que trata de colocarse entre una hermenéutica unívoca, que pretende interpretaciones claras y distintas, rigurosas y exactas, de los textos (cosa que creo que en las humanidades no se puede alcanzar), pero que también trata de evitar la hermenéutica equívoca, la cual se hunde en un mar de interpretaciones oscuras y confusas, irremediablemente ambiguas e inexactas, y que produce un relativismo excesivo en la comprensión. De esta manera creo que se puede ayudar a la filosofía hermenéutica, tan presente en las corrientes de hoy, a tener una perspectiva más adecuada y cultivar un terreno más fértil en esta hora de crisis de la filosofía.

\section{BIBLIOGRAFÍA}

Aubenque, P., 1989, "Sur la naissance de la doctrine pseudo-ariostotélicienne de l'analogie de l'être", en Les études philosophiques, 3/4.

Beuchot, M., 1993, "Poesía, mística y filosofía en San Juan de la Cruz", en La experiencia literaria, 1, UNAM, México.

${ }^{50}$ Rossi 1996, p. 11.

Diánoia, vol. LX, no. 74 (mayo de 2015). 
, 1996, "La hermenéutica mística y metafísica del Maestro Eckhart", en Divinitas, 39, Roma.

, 2002, La hermenéutica en la Edad Media, UnAM, México.

, 2004, "La phrónesis gadameriana y una hermenéutica analógica", en J.J. Acero, J.A. Nicolás, J.A. Pérez Tapias, L., Sáez, y J.F. Zúñiga (comps.), El legado de Gadamer, Universidad de Granada, Granada.

, 2006, "Peirce y el concepto de analogía", en E. Sandoval (comp.), Semiótica, lógica y conocimiento. Homenaje a Charles Sanders Peirce, UACM, México.

——, 2007a, Phrónesis, analogía y hermenéutica, UnAM, México.

-, 2007b, "La phrónesis o prudencia como constitutivo de la hermenéutica analógica. Su papel en la interpretación de la cultura", en Estudios Filosóficos, LVI, Valladolid.

—_ 2009, "Analogía e iconicidad en Peirce, para la hermenéutica", en Studium, XII/23, Argentina.

—_ 2012, La racionalidad analógica en la filosofía mexicana, Torres Asociados, México.

Black, M., 1964, Modelos y metáforas, trad. V. Sánchez de Zavala, Tecnos, Madrid.

Bochenski, I.M., 1962, “On Analogy”, en A. Menne (comp.), Logico-Philosophical Studies, Reidel, Dordrecht.

de Libera, A., 1991, La filosofía medioevale, Il Mulino, Bolonia.

Derrida, J., 1989, "La mitología blanca. La metáfora en el terreno de la filosofía", en J. Derrida, Márgenes de la filosofía, trad. C. González Marín, Cátedra, Madrid.

Diels, H. y W. Kranz, 1967, Die Fragmente der Vorsokratiker, Weidmann, Dublín/Zurich.

Domingo Moratalla, A., 1991, El arte de poder no tener razón. La hermenéutica dialógica de H.-G. Gadamer, Universidad Pontificia de Salamanca, Salamanca.

Eco, U., 1992, Los límites de la interpretación, trad. H. Lozano, Lumen, Barcelona.

Ferraris, M., 2002, Historia de la hermenéutica, trad. A. Perea Cortés, Siglo XXI, México.

Gadamer, H.G., 1977, Verdad y método. Fundamentos de una hermenéutica filosófica, trad. A. Agud Aparicio y R. de Agapito, Sígueme, Salamanca.

$\longrightarrow$, 1994, Verdad y método II, trad. M. Olasagasti, Sígueme, Salamanca.

Grenet, P.B., 1948, Les origines de l'analogie philosophique dans les dialogues de Platon, Boivin, París.

Grondin, J., 2003, Introducción a Gadamer, trad. C. Ruiz-Garrido, Herder, Barcelona.

—_ 2006, L'herméneutique, Presses Universitaires de France, París.

Jakobson, R., 1986, "Lingüística y poética", en Ensayos de lingüística general, trad. J.M. Pujol y J. Cabanes, Artemisa, México. 
Kant, I., 1958, La crítica del juicio, trad. M. García Morente, Librería General Victoriano Suárez, Madrid [1a. ed.: 1790].

Nolte, E., 1998, Heidegger. Política e historia en su vida y pensamiento, trad. E. Lucena, Tecnos, Madrid.

Peirce, Ch.S., 1970, Deducción, inducción e hipótesis, trad. J. Martí Ruiz-Werner, Aguilar, Buenos Aires.

—_ 1974, La ciencia de la semiótica, trad. A. Sercovich, Nueva Visión, Buenos Aires.

_ 1988 , "La crítica de los argumentos" (1892), en Ch.S. Peirce, Escritos

lógicos, ed. y trad. P. Castrillo, Alianza, Madrid.

Pieper, J., 1998, Sobre los mitos platónicos, trad. C. Gancho, Herder, Barcelona. Ramírez, J.M., 1970, De analogía, t. I, CSIC, Madrid.

Ricœur, P., 1969, "La simbólica del mal", en P. Ricœur, Finitud y culpabilidad, trad. C. Sánchez Gil, Taurus, Madrid.

— 1982, "The Task of Hermeneutics", en J.B. Thompson, (comp.), Paul Ricœur, Hermeneutics and the Human Sciences, Cambridge University Press/ Éditions de la Maison des Sciences de l'Homme, Cambridge-París.

— 1995, Teoría de la interpretación. Discurso y excedente de sentido, trad. G. Monges Nicolau, Siglo XXI/UIA, México.

— 1997, Autobiografía intelectual, trad. P. Willson, Nueva Visión, Buenos Aires.

Rodríguez, R., 1997, La transformación hermenéutica de la fenomenología. Una interpretación de la obra temprana de Heidegger, Tecnos, Madrid.

Rossi, A., 1996, "Cartas credenciales", discurso de ingreso a El Colegio Nacional, en Vuelta, año Xx, no. 233, abril de 1996.

Russell, B., 1960, "Vaguedad", en M. Bunge (comp.), Antología semántica, Nueva Visión, Buenos Aires.

Saussure, F. de, 1988, Curso de lingüística general, trad. M. Armiño, Fontamara, México.

Schleiermacher, F.D.E., 1987, Herméneutique, trad. al francés M. Simon, Labor et Fides, Ginebra.

Secretan, Ph., 1984, Lanalogie, Presses Universitaires de France, París.

Selvaggi, F., 1955, Filosofía de las ciencias, trad. A. Álvarez de Linera y Grund, Sociedad de Educación Atenas, Madrid.

Thomas de Vio, cardinalis Caietanus, 1952, De nominum analogia, N. Zammit y H. Hering (eds.), Institutum Angelicum, Roma.

Villoro, L., 1998, Estado plural, pluralidad de culturas, UNAM/Paidós, México.

Volpi, F., 1976, Heidegger e Brentano. L'aristotelismo e il problema dell'univocità dell'essere nella formazione filosofica del giovane Martin Heidegger, CEDAM, Padua.

Wittgenstein, L., 1973, Tractatus logico-philosophicus, trad. E. Tierno Galván, Alianza, Madrid [1a. ed.: 1921].

Recibido el 25 de octubre de 2014; aceptado el 5 de febrero de 2015. 